\title{
ORGANIZAÇÃO DO TRABALHO PEDAGÓGICO EM ESCOLAS DO CAMPO DO ESTADO DE MATO GROSSO, NOS ANOS DE 1980 E 1990
}

\author{
ILMA FERREIRA MACHADO ${ }^{1}$ \\ ORCID: http://orcid.org/0000-0001-5253-7684 \\ HELOISA SALLES GENTIL ${ }^{2}$ \\ ORCID: http://orcid.org/0000-0001-8299-208X
}

\begin{abstract}
RESUMO: Busca-se, neste texto, analisar como se configurava o trabalho pedagógico em escolas do campo do estado de Mato Grosso, nas décadas de 1980 e 1990. O estudo pauta-se na abordagem crítico-dialética e na pesquisa qualitativa, tendo como instrumento a entrevista semiestruturada, realizada com 23 professores. Os resultados apontam que as escolas não tinham uma proposta pedagógica definida; o trabalho pedagógico baseava-se nas orientações das secretarias de educação e nas experiências escolares dos professores; embora a educação no período em questão estivesse centrada nos aspectos instrucionais, alguns professores tentavam realizar um ensino humanizado, pautado na colaboração com alunos e pais/mães. A partir dos anos de 1990, o trabalho pedagógico passa a ocorrer de forma mais sistematizada e crítica, buscando incorporar a pesquisa como princípio pedagógico e a realidade do campo como laboratório vivo e fator de promoção da relação teoria-prática e da aprendizagem. Conclui-se que o trabalho pedagógico das escolas do campo, no período aqui recortado, é marcado por enormes desafios em termos da própria existência dessas escolas, da garantia de acesso dos trabalhadores rurais à educação escolar e da precariedade das condições de trabalho - estrutura física, recursos didáticos e formação/reconhecimento profissional. O processo de democratização do Brasil abre caminhos para se pensar em políticas públicas para a educação do campo, o que se intensificará no fim dos anos de 1990 e início dos anos 2000 .
\end{abstract}

Palavras-chave: educação do campo, trabalho pedagógico, Mato Grosso.

\section{ORGANIZATION OF PEDAGOGICAL WORK IN RURAL SCHOOL OF THE STATE OF MATO GROSSO AT THE YEARS 1980 AND 1990}

ABSTRACT: This article seeks to analyze how the pedagogical work in rural school of the state

\footnotetext{
${ }^{1}$ Universidade do Estado de Mato Grosso (UEMAT). Cáceres, MT, Brasil. <ilma.ferreirmachado@gmail.com>

2 Universidade do Estado de Mato Grosso (UEMAT). Cáceres, MT, Brasil. <logentil2@gmail.com> 
of Mato Grosso was configured in the 1980s and 1990s. This study is based on the criticaldialectical approach and the qualitative research, having as instrument the semi-structured interview with 23 teachers. The results indicate that the schools did not have a defined pedagogical proposal. The pedagogical work was based on the orientations of the departments of education and on the teachers' school experiences; although education in the period was focused on instructional aspects, some teachers tried to perform humanized teaching based on collaboration with students and parents. From the 1990s, pedagogical work started to take place in a more systematic and critical way, seeking to incorporate research as a pedagogical principle and the reality of the rural world as a living laboratory and as factor for the promotion of the theory-practice relationship and learning. We conclude that the pedagogical work of the rural school, during this period, is marked by enormous challenges in terms of the very existence of these schools, the guarantee of rural workers' access to school education and the precarious working conditions - physical structure, teaching resources and professional recognition and training. Brazil's democratization process opens the way to think public policies for rural education, which grew in the late 1990s and early 2000s.

Keywords: rural area education, pedagogical work, Mato Grosso.

\section{ORGANIZACIÓN DEL TRABAJO PEDAGÓGICO EN ESCUELAS RURALES DEL ESTADO DE MATO GROSSO EN LOS AÑOS DE 1980 Y 1990}

RESÚMEN: Este artículo busca analizar cómo se configuró el trabajo pedagógico en las escuelas rurales del estado de Mato Grosso en las décadas de 1980 y 1990. El estudio se basa en el enfoque crítico-dialéctico y la investigación cualitativa, teniendo como instrumento la entrevista semiestructurada, realizada a 23 docentes. Los resultados indican que las escuelas no tenían una propuesta pedagógica definida; el trabajo pedagógico se basaba en las orientaciones de las secretarías de educación y en las experiencias escolares de los docentes; aunque la educación en el período en cuestión se centró en aspectos de instrucción, algunos maestros trataron de llevar a cabo una enseñanza humanizada, cimentada en la colaboración con estudiantes y padres de familia. A partir de la década de 1990, el trabajo pedagógico se realizó de una manera más sistemática y crítica, buscando incorporar la investigación como un principio pedagógico y la realidad del campo como laboratorio vivo y factor de promoción de la relación teoría-práctica con el aprendizaje. Se concluye que el trabajo pedagógico de las escuelas rurales durante este lapso de tiempo está marcado por enormes desafíos para la existencia misma de estas escuelas, la falta de garantía para el acceso de los trabajadores rurales a la educación escolar, precarias condiciones de trabajo, estructuras físicas deficientes, escasos recursos didácticos, al igual que formación y reconocimiento profesional. El proceso de democratización del Brasil abre caminos para pensar políticas públicas para la educación en contextos rurales, lo que se intensificará a finales de la década de 1990 y principios de la década de 2000.

Palabras clave: educación en contextos rurales, trabajo pedagógico, Mato Grosso. 


\section{INTRODUÇÃO}

A educação escolar no campo no Brasil data do segundo reinado, e seu desenvolvimento histórico acompanha a evolução das estruturas socioagrárias do País (CALAZANS, 1993), marcadas pela concentração de terras e de riquezas, o que explica, em grande parte, porque essa educação nunca se constituiu em uma preocupação por parte dos governantes e da elite agrária. Com o advento da monocultura cafeeira, aliada ao fim da escravidão, ocorreu um pequeno impulso nessa área, o que passou a mostrar a necessidade de um tipo de trabalhador mais especializado, correspondendo à qualificação pretendida pelos grandes proprietários.

O movimento conhecido como ruralismo pedagógico, nos anos de 1930, defendeu uma "escola rural típica", com currículos e métodos adequados às peculiaridades regionais. Louvado como uma alternativa às tradicionais propostas educativas, na realidade esse movimento tinha como fundamento político-ideológico o ajustamento ou enraizamento do homem ao campo, de modo a atender a vocação rural do País e a "livrá-lo" do inchaço urbano e dos possíveis problemas sociais acarretados por esse fenômeno (CALAZANS, 1993). Em períodos posteriores, importaram-se para o campo projetos educacionais europeus e norte-americanos, enfatizando-se uma formação técnica, articulada aos princípios do mercado capitalista. Inúmeros foram os projetos implantados, ora pela iniciativa privada, ora pelo Estado, sempre na tentativa de submeter o campo à lógica do capital (VENDRAMINI, 2009; CALDART, 2010).

Até as décadas finais do século XX, as propostas educacionais trataram de simples transposição de um modelo educacional urbano para o campo, preconizando, na realidade, o fim deste, face ao acelerado desenvolvimento urbano impulsionado pelo avanço tecnológico, pela expansão do agronegócio (MOLINA; FERNANDES, 2004) e da economia globalizada. Procurouse limitar a educação dos sujeitos do campo à prática pela prática, prescindindo do conhecimento científico e tecnológico, uma vez que se entendia que a lógica de produção e trabalho do camponês devia ser eliminada (CALDART, 2010).

Pesquisas sobre a educação no campo (VENDRAMINI, 2009; PERIPOLLI, 2010; MOLINA; ANTUNES-ROCHA, 2014; SOUZA, 2018) têm sido realizadas, mas há poucas investigações sobre processos pedagógicos em escolas do campo em Mato Grosso nas décadas de 1980 e 1990. Em função disso, problematizam-se: como e em quais condições se deu a organização do trabalho pedagógico - OTP -, das escolas do campo nas décadas de 1980 e 1990 no estado de Mato Grosso? O principal objetivo é analisar, portanto, como se configurava o trabalho pedagógico em escolas do campo do estado de Mato Grosso, nesse período.

De acordo com Rocha (2010), na década de 1980 havia, no estado de Mato Grosso, 254.586 crianças na faixa etária de obrigatoriedade escolar, mas 80.103 estavam fora da escola, pois as 1.844 unidades escolares não eram suficientes para atender a demanda. Em 2017, segundo dados do Censo Escolar, o sistema educacional desse estado atendia 878.515 alunos, somando-se as redes pública e privada. Mato Grosso possui uma área de $903.546,42 \mathrm{~km}^{2}$ com enormes diferenças regionais e com uma ocupação territorial desigual. Em 1978, contava com 2.020.581 habitantes (ROCHA, 2010) e, quarenta anos depois, totalizava uma população de 3.441 .998 habitantes (IBGE, 2018); a densidade demográfica é de 3,3 habitantes por $\mathrm{km}^{2} ; 81,9 \%$ da população vive na zona urbana, e $18,1 \%$ na zona rural ${ }^{3}$.

Este trabalho referencia-se na abordagem crítico-dialética e na pesquisa qualitativa (GAMBOA, 2012). Parte do pressuposto de que a compreensão da realidade implica uma rigorosa análise das dimensões objetivas e subjetivas que ela comporta, assim como das contradições que a permeiam e que não permitem definições mecânicas e fechadas sobre um dado fenômeno, mas

\footnotetext{
${ }^{3}$ Disponível em:

http://www.seplan.mt.gov.br/documents/363424/11245058/Cen $\% \mathrm{C} 3 \%$ A 1 rio + Socioecon $\% \mathrm{C} 3 \% \mathrm{~B} 4 \mathrm{mico}+\mathrm{v}+1.0 .0$ 1+ conclu\%C3\%ADdo+20190329.pdf/05c8f4d6-4bbb-ff02-c122-e6518a6ae1a8. Acesso em: 30 nov. 2020. 
sim sínteses provisórias e sujeitas a novos questionamentos. Consideram-se, portanto, "os indivíduos reais, a sua ação e as suas condições materiais de vida, tanto as que encontraram, quanto as que produziram pela sua própria ação" (MARX, 2009, p. 23).

Esta pesquisa constou de análise de documentos sobre as políticas educacionais que, de uma forma ou de outra, se relacionavam à educação do campo no estado de Mato Grosso e de entrevistas semiestruturadas ${ }^{4}$ com professores da educação do campo, nas décadas de 1980 e 1990. Neste texto, analisam-se apenas os dados obtidos via entrevistas, abordando a organização do trabalho pedagógico, seus princípios, métodos, recursos materiais e didáticos, relação entre os sujeitos envolvidos no processo educativo e articulação com instâncias político-administrativas. Os dados foram organizados em quatro dimensões, a seguir, tendo-se ciência de que, na realidade, elas se entrelaçam: condições de trabalho; orientações e acompanhamento do trabalho pedagógico; princípios e fundamentos do trabalho pedagógico; e organização do trabalho pedagógico. A formação de professores é um eixo "transversal” à discussão sobre OTP.

Os sujeitos desta pesquisa foram 23 professores da educação do campo nas décadas de 1980 e 1990, de cinco mesorregiões do estado: norte, centro-sul, sudeste, sudoeste e nordeste, identificados e localizados por meio de consulta aos arquivos da Secretaria de Estado de Educação de Mato Grosso ou indicação de pessoas envolvidas com a educação do campo. Da região nordeste, entrevistaram-se educadores dos municípios de São Félix do Araguaia e Cascalheira; da região sudoeste, educadores de Mirassol D'Oeste e Tangará da Serra; da região centro-sul: educadores de Cuiabá e Cáceres; da região norte: educadores de Comodoro, Sinop e Nova Canaã; e da região sudeste, educadores de Rondonópolis e São José do Povo. Foram entrevistados cinco professores de cada uma dessas regiões, à exceção da região centro-sul, em que apenas três participaram; as pessoas entrevistadas foram identificadas pelas letras iniciais dos nomes, seguidas da região e ano em que a entrevista foi realizada. As entrevistas, com duração de uma a duas horas, em sessão única com cada participante, foram gravadas e transcritas. A título de contextualização, cabe dizer que cerca de $80 \%$ dos entrevistados são do sexo feminino, incluindo-se os professores formadores; o tempo de atuação na educação do campo varia de um a vinte anos; três dessas professoras atuaram, também, nos anos de 1970, quatro não atuaram na década de 1980, apenas na década de 1990. Duas professoras são aposentadas, porém continuam atuando, voluntariamente, em projetos sociais.

\section{CONDIÇÕES DE TRABALHO}

Nessa dimensão, destacam-se aspectos como infraestrutura, condições de acesso à escola e formação dos professores.

Nos anos de 1980, entre os participantes desta pesquisa, predominava a formação correspondente ao ensino fundamental - dos 19 professores, 11 possuíam o ensino fundamental; e nos anos de 1990, predominava a formação no ensino médio - no fim dessa década, começa a aparecer a formação em educação superior. De acordo com Rocha (2010, p.30), “em 1979, dos 2.217 professores que atuavam na zona rural em Mato Grosso, apenas 138 tinham o magistério como qualificação". Há casos em que, na década de 1980, a pessoa não tinha nem mesmo a idade mínima de 18 anos, permitida para ser contratada como professora, conforme evidenciado no relato dessa professora da região sudeste: "Então, eu trabalhava com uma colega que ia lá e pegava as aulas, mas era eu que ia para a escola" (Fa.SE, 2014); e de outra da região nordeste: "Na época, teve outras meninas também que entraram bem novinhas e começaram a trabalhar porque não tinha quem" (Li.NE, 2015).

O perfil dos professores entrevistados é um demonstrativo da pouca ou quase

\footnotetext{
${ }^{4}$ Utilizaram-se entrevistas semiestruturadas como procedimento para obtenção de informações, fontes orais de dados específicos, em função de objetivos definidos; não se pretendeu em nenhum momento fazer estudo da memória. Educação em Revista|Belo Horizonte|v.37|e229231|2021
} 
inexistente atenção dispensada à formação dos professores das escolas do campo no Brasil até os anos finais do século XX. No período em questão, não foi apontada pelos entrevistados a existência de políticas específicas de educação do campo, o que existia "Era pra rede. Pra educação do campo não, não tinha essa diferença não" (Lu.SO, 2014). Portanto, os educadores dessa modalidade de educação eram "atendidos" por políticas generalistas: "parecia que era tudo da zona urbana, não tinha muita diferença. Então, a educação do campo nunca foi tratada assim, com um olhar diferenciado, nunca percebi" (Ma.N, 2015). A formação, quando ocorria, era pensada de forma geral, "para" os professores, e não com eles, sem distinção de urbano e do campo. Não foi possível identificar a perspectiva ou o movimento coletivo de planear uma educação/formação dos trabalhadores a partir e em função de seus interesses sociais, políticos e humanos, uma luta por um direito específico dentro da luta maior por direitos (CALDART, 2015).

Durante muito tempo, o exercício do magistério foi uma ocupação associada à ideia de missão, e isso fez com que não houvesse grande preocupação com a formação, especialmente para os anos iniciais da escolarização. Em todo o País, os professores dessa fase e, mais especificamente da zona urbana, eram formados, quando muito, em nível médio, no "Curso Normal" (magistério). A legislação (Lei 4.024/61) chegou a permitir a formação de professores tanto em nível ginasial como em nível secundário, além do nível universitário, diferenciando-se apenas a nomenclatura e o nível de atuação. No primeiro caso, os professores eram chamados regentes de ensino primário; professor primário era o que se formava no secundário; e os que conseguiam uma formação universitária se tornavam professores de ensino médio.

Dadas as dificuldades da vida na zona rural naquele período, mais complicado se tornava ser professor nas escolas do campo, como narram alguns dos entrevistados:

Eu comecei minha militância (a educação né?), em 82-83 em Alto Araguaia [...] lembro que o ônibus deixava a gente no asfalto, e aí para chegar na fazenda a gente ia a cavalo, a gente pendurava uma malinha nesse cavalinho e chegava na escola [...] a maioria dos meus alunos vinha a cavalo [...] (Fa.SE, 2014).

Eu comecei a lecionar em dois períodos [...] Tinha que ir a pé, era muito difícil [...] tinha dificuldades de estrada, enchente na escola (Jo.N, 2014).

As dificuldades estruturais da educação rural/do campo são relatadas, também, por Davis e Gatti (1993), Molina et. al (2009); Ribeiro (2010). Nesse contexto, as chamadas "escolinhas rurais" encontravam-se instaladas nas fazendas e sítios, geralmente eram (e em muitos lugares ainda são) constituídas por uma sala de aula onde se concentravam crianças de diversas fases de escolaridade, sob a orientação de uma única professora. Toda a organização e o funcionamento da escola se davam pela ação do professor, que, além da docência, assumia as atividades cotidianas de limpeza e preparação da merenda, bem como as atividades administrativas de sua unidade escolar, tal como apontado por Rocha (2010) e corroborado por depoimentos desta pesquisa:

Foi em 91, fui para a escola! Cheguei lá, tinha que limpar a escola, fazer merenda e dar aula para $1^{\mathrm{a}}, 2^{\mathrm{a}}, 3^{\mathrm{a}}$ e $4^{\mathrm{a}}$ série tudo misturado; não tinha água, tinha que buscar no córrego, e eu chegava cedo, ia de bicicleta, eram $25 \mathrm{~km}$ para ir e $25 \mathrm{~km}$ para voltar, eu andava 50 $\mathrm{km}$ aqui na estrada de Cuiabá pra ir para essa escola dar aula (Wi.SE, 2015).

Até 99, o trabalho de um professor na sala de aula era tudo. Ele era professor, secretário, merendeiro, faxineiro, ele fazia tudo. Todo trabalho era desenvolvido pelo professor, às vezes com parceria dos alunos, cooperação [...] por que você não dava conta de tudo. Nessa época então, o nosso salário era bem pequenininho [...] (Ce.N, 2014).

Evidencia-se, nessa situação, para além da sobrecarga de trabalho, a pouca profissionalização do trabalho do professor. As precárias condições de trabalho docente e de funcionamento das escolas retratam o histórico descaso enfrentado pela educação rural, uma vez 
que aqueles que teriam acesso a ela seriam os filhos de trabalhadores, e não dos grandes proprietários de terra, que estudavam em escolas da cidade e até no exterior. A municipalização do ensino fundamental, também, provocou "uma omissão em relação à escola do campo, já que grande parte das prefeituras não possuía recursos suficientes para a manutenção das mesmas" (CASAGRANDE, 2007, p.60).

No fim de 1980 e nos anos de 1990, período de intenso processo de urbanização do estado de Mato Grosso, foram organizados pela Secretaria de Estado de Educação alguns programas e projetos de formação de professores leigos (aqueles que não possuíam habilitação para o magistério), incluindo as denominadas escolas rurais. Dentre os projetos que visavam a habilitação para o Magistério, podem-se citar o Inajá (1987), o Homem Natureza (1990), o GerAção (1997) e o Tucum (1995) - específico para professores indígenas (ROCHA, 2010).

\section{ORIENTAÇÕES E ACOMPANHAMENTO DO TRABALHO PEDAGÓGICO}

Neste item, busca-se analisar como as professoras desenvolviam o trabalho pedagógico, que orientações recebiam para tal e como se davam as relações institucionais.

Compreende-se o trabalho pedagógico como "o modo de organização que a escola assume na tarefa de pensar e produzir as relações de saber entre sujeitos e o mundo concreto, o mundo do trabalho socialmente produtivo" (MACHADO, 2003, p.246), e que guarda relações com o modo de organização socioeconômica da sociedade na qual a escola está situada. Para Frizzo (2008), é um tanto arriscado, e até difícil, reduzir o significado do trabalho realizado nas escolas a uma prática - prática pedagógica, prática docente - porque, dessa forma, se desloca o eixo da problematização do trabalho pedagógico, na qualidade de atividade humana intelectual entendida como práxis humana (FRIZZO, 2008). O trabalho pedagógico "é uma prática social que atua na configuração da existência humana individual e grupal para realizar nos sujeitos humanos as características de seres humanos" (FRIZZO, 2008, p. 5). A organização do trabalho pedagógico não se dá aleatória e ingenuamente, ela é sustentada por "um conjunto de princípios filosóficos, políticos e epistemológicos definidores das normas e ações escolares" (MACHADO, 2009, p. 10), que orientam as práticas pedagógicas e as relações efetivadas entre os sujeitos da escola. A OTP constitui-se como uma dimensão da teoria pedagógica, que contém proposições de materialização do trabalho pedagógico e se articula a uma teoria educacional, a qual envolve a concepção de educação, sociedade e sujeitos, apoiada em um projeto histórico de sociedade (FREITAS, 1995). Ela abrange o trabalho pedagógico global da escola - Projeto Político Pedagógico, PPP - e da sala de aula, e implica pensar os conteúdos, as metodologias e as finalidades que articulam tais ações. Significa, pois, pensar o currículo com os saberes e as práticas pedagógicas que serão priorizadas, a organização do ensino, o tempo escolar e a avaliação.

De acordo com as falas das professoras entrevistadas, as orientações políticopedagógicas que as escolas do campo recebiam nos anos de 1980 e 1990 emanavam da Secretaria de Educação do Estado - Seduc/MT - e das Secretarias Municipais de Educação - SME -, observando-se as recomendações e os indicativos do Ministério da Educação - MEC. De início, as orientações eram realizadas por meio de visitas e assessorias pedagógicas às escolas, com uma periodicidade que, de um modo geral, variava de 15 a 60 dias; depois, passaram a ocorrer também por meio dos cursos. A precariedade do transporte e das estradas dificultava o acesso das assessorias às escolas, bem como dos professores às secretarias de educação.

Não tinha muito apoio pedagógico, por que as escolas eram pequenas e a gente ficava um pouco isolado da Secretária de Educação, da Coordenação Pedagógica. Era sempre muito longe! Se a gente precisava de algum recurso junto à direção da escola, tinha que viajar algumas horas de bicicleta ou de carona pra tentar solucionar os problemas que surgiam nas escolas (Ze.CS, 2014). 
Outras entrevistadas, também, apontam que nos anos de 1980 prevaleciam as visitas periódicas de representantes das secretarias de educação às escolas do campo:

Nós tínhamos visitas até mesmo da Secretária, que se dispunha a participar do processo com a gente, trabalhar a alfabetização passo-a-passo. Era bem rígida a questão, os dias letivos. Marcavam as reuniões em um polo, iam buscar a gente nas escolas e levava até esse polo, e lá a gente confeccionava trabalhos e muitos tipos de cartazes [...] tinha uma supervisora que ia de mês em mês, dependendo, se a gente tinha algum problema na escola, era mais frequente a visita (Ce.NE, 2014).

Tinha coordenação da Secretaria que ia às escolas rurais, em uma Kombi [...] visitava e ia ver como você estava trabalhando, que processo, que era o "bê-a-bá", se as crianças tinham rendimento [...] (Fa.SE, 2014).

De acordo com uma professora da região centro-sul, a escola sempre recebia visitas da SME; quando era preciso, essa professora ia à Secretaria, onde havia uma pessoa responsável por sua escola, com a qual ela procurava resolver os problemas administrativos e pedagógicos; ela fazia contatos com outros professores e escolas, e isso ajudava muito, pois "conseguia até materiais para melhorar as aulas" (Or.CS, 2014). Note-se que a professora "conseguia" materiais, portanto, não havia uma política de oferta de material às escolas do campo.

Há pequenas controvérsias nos depoimentos de professores de uma mesma região sobre a forma de orientação pedagógica; falam sobre orientação e planejamento em grupo, mas também sobre a falta de acompanhamento: "Pra começar o ano letivo, existia uma semana pedagógica, onde normalmente a gente vinha para a cidade participar [...] ou então a gente reunia todas as escolas do campo em um polo" (Ze.CS, 2014). Esse mesmo professor explica que, após esse período: "O acompanhamento pedagógico não tinha, a gente recebia visitas do diretor, do coordenador, mas isso era uma coisa de 2 em 2 meses ou, dependendo da distância das escolas, até mais".

O caráter da orientação pedagógica que ocorria por parte das secretarias de educação é registrado, ainda, por uma professora da região norte:

[...] nós recebíamos as instruções da secretaria de educação e da coordenadora das escolas do campo, que era chamada de diretora das escolas do campo, das escolas rurais. Decidia reunir, então, professores das diversas comunidades, e cada um falava da sua experiência, mas não tinha uma formação pedagógica, assim, científica [...] A formação era mais assim: "Quais são as dificuldades?”, “O que cada um está fazendo?”[...] É meio que um receituário, que eu acho que precisa, muitas vezes, pra gente sair de algumas situações [...] (Mi.N., 2015).

É possível perceber que não havia uma política de acompanhamento ou de formação continuada definida, eram ações pontuais de atendimento a necessidades e tentativa de solução de alguns problemas, incluindo-se aqueles relativos à alfabetização, algumas vezes por meio da troca de experiências. Rocha (2010) registra que houve uma proposta de formação assumida pelo Estado em meados dos anos 1970 (Projeto Novas Metodologias), cuja preocupação específica eram os índices de alfabetização, aprovação e reprovação nos anos iniciais, mas que não atingia todo o território de Mato Grosso.

Os desafios do processo de orientação pedagógica nos anos de 1980 são registrados, também, por professoras formadoras. Uma professora da região centro-sul, município de Mirassol D'Oeste, argumenta que, inicialmente, o planejamento de ensino anual era centralizado: os professores das escolas rurais deslocavam-se para a cidade para participar, durante quatro ou cinco dias, dessa atividade, deixando a família no campo. Contudo, a partir do terceiro dia, começava a ocorrer um esvaziamento, os maridos iam buscar as esposas-professoras, desmobilizando o processo de capacitação e dificultando a apropriação dos fundamentos teórico-práticos abordados; 
o que acabava acontecendo é que muitos professores iam aos cursos de formação "cumprir sua obrigação, mas lá na escola não, pegava o livro e seguia a didática do livro lá. Então, o planejamento era uma formalidade" (Ma.CS, 2014). Assim, a equipe de formação da SME daquele município resolveu mudar de estratégia, agrupando professores e realizando a formação em núcleos mais próximos, inclusive pensando a formação em função das "possibilidades do lugar" (Ma.CS, 2014). Eram práticas de formação continuada, denominadas, à época, de cursos de treinamento, de capacitação ou até de reciclagem, que ganharam maior ênfase e institucionalidade na década de 1990.

O sentido de formação continuada é referente àquela que ocorre em estudos e/ou reflexões específicos sobre os processos educativos, suas concepções e práticas, seus referenciais e, também, no conjunto de experiências vividas por sujeitos que são professores e atuam na docência, quer sejam proporcionadas (as reflexões e as experiências) por cursos de habilitação ou qualificação, quer provenientes das práticas profissionais cotidianas nas instituições educativas ou de suas vivências em outros âmbitos sociais (GENTIL, 2005, p.64).

Uma professora formadora relata que se sentava com o professor para ensinar a fazer o planejamento para cada dia da semana, porém, nada que envolvesse uma discussão mais elaborada e aprofundada: "Era uma coisa muito tateando, muito começando. Eu também tinha o quê, 23, 24 anos, 25, né? E, também, estava me formando nessa situação, nesse contexto de ser supervisora do campo" (Ma.SE, 2015). Pode-se associar a fala dessa formadora à ideia do aprender enquanto se ensina (c, 2002), ainda que de maneira um tanto intuitiva.

Cabe observar que nos anos de 1980 vigorava a LDB n ${ }^{\circ} 5.692 / 71$, que ampliou a obrigatoriedade escolar de 4 para 8 anos de idade e passou a dar ênfase ao ensino de cunho profissionalizante e técnico no segundo grau, em contraposição ao ensino humanístico. Com a aprovação da LDB $n^{\circ}$ 9.394/1996, há um reordenamento na estrutura educacional e uma ampliação no conceito de educação, que passa a contemplar tanto os espaços formais quanto os não formais, e a fazer referências à educação em espaços rurais (Art. 28); consta dessa Lei, também, a obrigatoriedade da formação de professores em nível superior.

Nos anos de 1990, ampliaram-se as orientações de cunho didático-pedagógico, como relata essa professora: "A gente vinha para o centro aqui, era mesmo dentro de Comodoro, a gente tinha todo o início e meio do ano aqueles cursos para o processo de alfabetização" (Ce.N, 2014). Muitos desses cursos eram realizados em período das férias escolares: "Todo o período de férias a gente tinha um encontro mais longo em que, às vezes, vinham até uns professores de fora [...] No período de férias a gente nunca ficava desocupado, sempre quando era julho a gente tinha 15 dias de encontro" (Li.NE, 2015).

As orientações aos professores aconteciam, preferencialmente, durante as semanas pedagógicas - um ensaio de formação continuada mais institucional e direcionada, de exercício coletivo, mas incluindo também visitas de técnicos das Secretaria Municipais de Educação às escolas do campo.

Nós não tínhamos muito a quem recorrer. Nesse período, você tinha que anotar suas dúvidas, esperar o dia que viessem, que era o dia de pagamento, o dia que eles fossem, né? Mas dava resultado [...] Com o passar do tempo, foram melhorando as visitas. Eles iam e davam sugestão, anotavam. Depois nas próximas visitas eles queriam ver o que que você fez das sugestões e ver os resultados. Sempre essa proposta, né? "Tal dia eu vim aqui e te dei a sugestão, o que melhorou naquele aluno tal...?” [...] (Ca.SO, 2014).

A formação na e pela prática parece ter sido a tônica do período, predominando o que Tardif (2007) denomina de saber experiencial e cultural, em detrimento do saber disciplinar ou de formação profissional, pois os professores. 
[...] em suas atividades profissionais se apoiam em diversas formas de saberes: o saber curricular, proveniente dos programas e dos manuais escolares; o saber disciplinar, que constitui o conteúdo das matérias ensinadas na escola; o saber da formação profissional, adquirido por ocasião da formação inicial ou contínua; o saber experiencial, oriundo da prática da profissão, e, enfim, o saber cultural herdado de sua trajetória de vida e de sua pertença a uma cultura particular, que eles partilham em maior ou menor grau com os alunos (TARDIF, 2007, p. 297).

Os depoimentos citados fornecem elementos para compreender, minimamente, como se davam as relações institucionais de atendimento, orientação e acompanhamento pedagógico entre as secretarias de educação e as escolas do campo, bem como possibilitam identificar como era problemática a organização do trabalho pedagógico. A gestão educacional nesse período era centralizada na figura do secretário municipal de educação e das delegacias regionais de ensino, instituídas pela Secretaria de Educação e Cultura/MT, no âmbito Grupo Direção e Assessoramento Superior. O acompanhamento às escolas do campo era feito, periodicamente, por assessores ou supervisores, vinculados às secretarias de educação; na maior parte das vezes, os professores viravam-se sozinhos, contando apenas com a ajuda dos pais e alunos. Como pensar em uma perspectiva mais crítica com trabalho coletivo e a auto-organização de educadores nessa situação de isolamento em que eles se encontravam na maior parte do tempo?

\section{PRINCÍPIOS E FUNDAMENTOS DO TRABALHO PEDAGÓGICO}

Nesta dimensão de análise, busca-se identificar em que princípios se pautavam os professores em suas práticas educativas. Alguns desses princípios puderam ser apreendidos nas entrevistas, a partir dos teóricos mencionados: "eu me lembro assim que ficava muito na parte da alfabetização, uma pessoa que muito citada era Emília Ferreiro, Vygotsky também era muito utilizado" (Ca.SO, 2014).

O período de democratização do País trouxe à tona uma série de questões e debates teóricos, entre eles, os referentes à alfabetização, cujos índices se configuravam como problema. Estava dada a possibilidade de ultrapassar o tecnicismo predominante até então, voltando-se o olhar para o sujeito que aprende, e não somente às técnicas de ensino. Ganhavam visibilidade as teorias construtivistas e sociointeracionistas; a pesquisa como eixo metodológico ganhou força nesse período nos projetos de formação de professores realizados em Mato Grosso, especialmente pela assessoria de professores da Unicamp (GENTIL, 2002).

Uma professora formadora, atuante na década de 1980, remete aos princípios da educação libertadora:

[...] o método Paulo Freire, embora não seja aplicado na íntegra, mas as ideias dele nos motivavam. O nosso caminhar era baseado nas ideias de Paulo Freire. E o planejamento era com base naquelas ideias, com base nos objetivos de conscientizar, de politizar, de tornar aquelas crianças críticas e autônomas, conhecedoras dos problemas que elas estavam vivendo (Ml..NE, 2014).

O que se percebe, pelos depoimentos, é que os encontros e os cursos de formação do fim dos anos 80 e início dos anos 90 tentavam introduzir perspectivas atualizadas para a época, aquelas que se voltavam para a compreensão dos estudantes como sujeitos da aprendizagem, exceto o LOGOS II, que adotava uma perspectiva tecnicista.

Em relação às professoras entrevistadas, pode-se dizer que, em grande parte, o ato de instruir não se descolava do ato de educar, e buscava-se estabelecer a relação entre conteúdos instrucionais e cotidiano dos alunos; os professores, com autoridade reconhecida pela comunidade, ajudavam a formar valores e visões de mundo, a maioria deles ligados à necessidade de respeito ao próximo e aos pais, de solidariedade e de envolvimento na distribuição de tarefas de organização 
do espaço escolar.

Era muito bom naquele tempo os alunos ajudavam, eles tinham cooperação de te ajudar na limpeza, de lavar as vasilhas da merenda. Parece que mesmo perdendo aquele tempo, você ganhava com outro aspecto, por exemplo, de já ter responsabilidade desde cedo, de cuidar, de ficar limpo, né? Hoje não, parece que encontra tudo pronto, então, não tem essa preocupação, joga lixo no chão [...] (Lu.SO, 2014).

De certa forma, configurava-se, nessas práticas pedagógicas, uma relação trabalhoeducação como um princípio educativo, manifestando-se o trabalho como algo necessário para a manutenção da vida escolar e como atividade da qual "ninguém pode fugir", mas não necessariamente como princípio educativo emancipador (FRIGOTTO; CIAVATTA; RAMOS, 2011; SILVA; ANDRIONI; MACHADO, 2017). O trabalho, em sua concepção emancipatória, implica questionar as relações sociais e produtivas, o modo de produção capitalista, com vistas a construir medidas de superação das relações de exploração do homem sobre o homem e forjar uma sociedade socialista.

$\mathrm{Na}$ região nordeste (Araguaia), caracterizada por intensos conflitos de terra, o trabalho pedagógico buscava, já nos anos de 1980, articular a discussão da questão da luta pela terra com a formação escolar, problematizando a realidade das famílias como forma de se chegar aos temas e palavras geradoras, que eram abordadas na perspectiva dos círculos de cultura, de Paulo Freire, como evidencia uma professora formadora:

[...] as palavras geradoras eram o ponto alto da alfabetização [...] é o que em Paulo Freire, chamava círculo de cultura, que está na Pedagogia do Oprimido. No círculo de cultura durava às vezes dias, projetava [as palavras geradoras] e daí o debate vinha vindo [...] haviam sido preparadas antes, tinha sido uma pesquisa que tinha levantado essas palavras chaves [...] (Ju.NE, 2015).

Um indicativo de projeto formativo em uma perspectiva mais crítica pode ser registrado, também, na fala dessa educadora:

[...] Eu via a educação do campo não como essa educação que hoje eu vejo em muitas escolas, ler, escrever, mas era uma educação muito mais completa, ou seja, que trabalhava muito as questões políticas, pública e estatal. Tanto é que a escola de [...] pra mim era a escola mais completa que você pode imaginar, por que lá trabalhava todos os conteúdos com muita qualidade, mas também tinha toda problemática política e social daquela comunidade, daquele distrito, e a escola era a responsável, trazia consigo essa discussão, esse encaminhamento das propostas, as intervenções que tinha que fazer, tudo era discutido na escola [...] (Ml.NE, 2015).

No fim dos anos 90, evidencia-se o delineamento da educação do campo em áreas de assentamento da reforma agrária, vinculados ao MST, já com alguns princípios e práticas nos moldes do movimento, em uma perspectiva crítica, com objetivos mais explícitos, ainda que em processo de construção.

[...] quem foi trabalhar nesses assentamentos já foi com esse objetivo e já sabia que a educação do campo ia ser diferente. Eles falavam "nós temos que fazer diferente". Os planejamentos eram coletivos, onde surgia as ideias, mas pegava todo o plano da Secretária, nós não fugíamos dele, nós transformávamos, por exemplo, se eu fosse passar um problema para o aluno, eu transformava esse problema falando sobre o campo, valorizando o campo, trazendo a realidade [...] (Mg.SE, 2015).

As questões apontadas na entrevista acima aproximam-se dos princípios assumidos pela educação do campo, que propõe trabalhar a atualidade (PISTRAK, 2002), buscando perceber 
as grandes questões ou problemáticas da prática social (trabalho, economia, cultura) que preocupam os sujeitos de uma dada comunidade e que necessitam ser compreendidas e transformadas mediante a intervenção compromissada dos sujeitos; têm, portanto, um caráter praxiológico, demarcado pela estreita articulação da escola com a vida dos estudantes e suas famílias. Este é um aspecto do qual a organização do trabalho pedagógico não pode se descuidar, quando o foco da escola é a formação humana e emancipatória.

Entende-se que o trabalho pedagógico precisa partir de problematizações, visando a conscientização sobre os valores humanos, a vivência constantemente recriada de conteúdos culturais e buscando formas democráticas de interação social. Portanto, "a concepção de educação deve contemplar uma visão de futuro que considera a condição humana como objeto essencial de todo trabalho pedagógico" (FRIZZO, 2008, p. 6-7).

\section{ORGANIZAÇÃO DO TRABALHO PEDAGÓGICO}

Os dados das entrevistas apontam que não havia uma proposta pedagógica ou um projeto pedagógico explícito para as escolas do campo; as orientações emanavam das secretarias/assessorias/supervisões pedagógicas e serviam para ajudar a organizar os planos de curso a cada início de ano (na semana pedagógica), que, por sua vez, se traduziam nas atividades que os professores desenvolviam com os alunos durante o ano letivo.

Um professor da região centro-sul expressa seu estranhamento quanto ao fato de as escolas do campo terem que seguir a proposta e a forma de organização da escola urbana:

\footnotetext{
Um dos fatos que me marcou bastante foi com relação ao calendário escolar, [...] o calendário era o calendário da zona urbana que a gente recebia lá na escola do campo, e a gente não tinha um calendário voltado para a nossa realidade do campo. Houve um momento que eu chamei o diretor da escola pra mudar o período de férias da escola, em função da colheita de algodão que ocorria e os alunos se afastavam das aulas pra colher algodão, isso nos anos 80 [...] O diretor ficou preocupado com a SME, com o secretário [...] e eu resolvi enfrentar o problema por conta própria e mudei as férias da escola (Ze.CS, 2014).
}

É interessante registrar o desconforto desse professor ao constatar que a organização escolar, espelhada em padrões urbanos, não favorecia a relação da escola, do currículo com a vida e trabalho da comunidade ou a articulação trabalho-educação. Estes aspectos, por vezes, figuravam nas propostas de alguns cursos de formação que se preocupavam com a compreensão do entorno da escola e tinham a realidade como uma dimensão que era preciso explorar.

Em uma pesquisa sobre escola rural, Davis e Gatti (1993) referiram-se à pouca "institucionalidade" da escola - mesmo com a ritualização das atividades partindo, certamente, do modelo de escola tradicional/capitalista. Entretanto, pelas evidências colhidas nas entrevistas, pode-se dizer que o formato das relações era padrão, muito institucional, especialmente nas relações com o conhecimento, ainda que frágeis em termos de domínio de conteúdo. De um modo geral, havia uma exigência externa e observância a um planejamento, com um conteúdo prédefinido pelas secretarias de educação, que era minimamente cobrado em termos de avaliação de aprendizagem; havia, também, a autoridade do professor como reconhecimento e marca dessa institucionalidade.

A organização do ensino configurava-se pela existência do professor unidocente e das turmas multisseriadas - marcas da atuação docente da maioria dos participantes desta pesquisa, conforme disposto no quadro abaixo. 


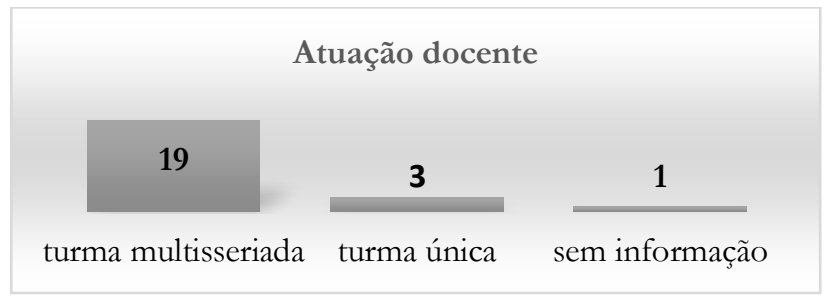

Fonte: organizado pelas pesquisadoras.

Uma professora da região centro-sul (Or. CS) disse que trabalhava com cerca de 30 alunos, com níveis de aprendizagem diferenciados. Para conseguir atender a todos, dividia o ambiente da sala de aula com duas lousas, formando, assim, duas turmas, uma virada para cada lousa. Essa forma de trabalho foi adotada também por um professor da região sudeste no início dos anos de 1990: "Eu cheguei lá, peguei os livros que tinha em uma prateleira lá e comecei. O de $1^{a}$ série passava no quadro de $1^{a}$ série, da $2^{\circ}$ passava para $2^{\circ}$, e ia copiando do livro, passando os exercícios e eles iam fazendo. Trabalhei com isso" (Wi.SE, 2015).

A inexperiência e a falta de formação específica impeliam alguns professores a agirem com base em suas vivências como estudantes (o saber experiencial), sem um discernimento maior sobre sua prática pedagógica, como foi o caso de uma professora da região nordeste (Li.NE, 2015): "quando eu comecei a trabalhar eu tinha feito a $1^{a}$ a $4^{a}$ série, então o que é que eu tinha? Nada, eu sabia ensinar o 'a, b, c,' porque era o que eu sabia, o que eu tinha, né?”. Educadores de outras regiões também falam da falta de formação, e mesmo de idade, para assumir a função docente:

A gente não tinha a orientação de ninguém para preparar as aulas. Você tinha que preparar as aulas baseado naquilo que você aprendeu na condição de aluno. Se eu aprendi a fazer conta de dividir, as quatro operações, ler problemas e interpretar problemas e eu tenho que fazer com que o aluno chegue no quarto ano fazendo a mesma coisa (Ja.N, 2015).

[...] em 80/81 recebi quase que uma convocação para assumir a sala de aula de uma escolinha do sítio, chamada de comunidade São Sebastião, a $13 \mathrm{~km}$ de Colíder [...] Eu, naquela época, tinha apenas 17 anos e tinha a 8 a série, que era o curso ginasial. Então eu já era considerada uma pessoa com estudo [...] (Mi.N, 2015).

Outros depoimentos retratam a realidade do professor e da professora leiga, a forma de organização do trabalho pedagógico e a dificuldade de se trabalhar com turmas multisseriadas:

[...] como eu era leiga na área, o que eu fazia? Eu dividia em quatro grupos dentro da sala de aula. Então cada canto da sala a gente colocava o grupo, não dava para trabalhar na lousa, eu trabalhava com cartazes, com papel pardo. A gente chamava ele de caderno ambulante, que a gente só ia fazendo e mudando a página, ia virando e na próxima aula a gente fazia outras atividades, quando era no final da semana você estava com calhamaço de papel, que era usado como se fosse a lousa (Va.NE, 2015).

Tinha aluno pequenininho, tinha aluno grande, já tinha aluno casado, então era aquela mistura de alunos, o que dificultava também [...] Aqueles mais velhos, às vezes, serviam até de monitor para os mais novos. Mas tinha sala de aula que a gente encontrava dificuldade, por que os alunos menores atrapalhavam, segundo os mais velhos (Ci.N, 2014).

Os dizeres tratam de situações das décadas de 1980 e 1990, mas é válido ressaltar que as escolas ou classes multisseriadas estão respaldadas pelo artigo 23 da LDB n ${ }^{\circ} 9.394 / 96$, que se refere a diferentes formas de organização do ensino. Porém, foi com a aprovação da Resolução $\mathrm{CNE} / \mathrm{CEB} n^{\circ}$ 2/2008 que se fez menção direta às escolas multisseriadas; estas são formadas, sobretudo, em localidades rurais em que há poucos alunos por séries, assim, "em uma mesma 
classe, são encontrados alunos com diferentes idades e diferentes etapas de escolaridade" (OLIVEIRA; OLIVEIRA, 2015, p. 225). Esses autores, com base em uma pesquisa realizada em anos mais recentes, também registraram a dificuldade de professores em lidar com essa forma de organização escolar - a multissérie -, no que tange ao planejamento e ao processo ensinoaprendizagem, uma vez que "exige a elaboração de estratégias variadas, para atender não apenas as diferentes necessidades de conteúdos, como também a grande variação de interesses e modos de interação resultante das diferenças de faixas etárias dos alunos" (OLIVEIRA; OLIVEIRA, 2015, p. 225).

$\mathrm{Na}$ análise dos dados da pesquisa, evidencia-se a contradição presente nas turmas multisseriadas: para a gestão e para as comunidades, era a garantia da existência da escola; para os professores com pouca formação, era o aumento das dificuldades. No entanto, promoviam-se formas de interação entre estudantes de séries diferentes, e praticamente se impelia o professor a uma prática pedagógica diferenciada:

[...] a sala de aula misturada, mesclada, multisseriada, eu não acho que é uma coisa condenável, é possível aprender, tanto é que acontecia isso lá na sala em que eu trabalhava, aqueles que terminavam antes, ajudavam os outros [...] eu não sei se os maiores não tiveram prejuízo eu penso até que sim, no sentido dos conteúdos lá do quarto ano, sabe? Mas, se a gente vai para o Paulo Freire, que quem ensina de repente aprende, então talvez eles estavam aprendendo né? (Mi.N, 2015).

Hoje [...], as classes multisseriadas são muito mal vistas, falam que o aluno não aprende tal e tal, mas aprende [...] (Ca.SO, 2014)

Os estudos de Hage (2006) e Arroyo (2010) contribuem para uma análise mais aprofundada sobre esse tema, destacando as potencialidades das salas multisseriadas, assim como a necessidade de políticas públicas para o desenvolvimento qualitativo do trabalho pedagógico nesses espaços.

É fala recorrente entre os entrevistados, que faziam um atendimento individualizado aos alunos e adotavam a estratégia de "passar mais tarefa" para cada um que terminava antes dos outros. No entanto, constata-se que havia momentos de trabalho de caráter um pouco mais coletivo e colaborativo em que os "mais adiantados" auxiliavam os iniciantes: "o aluno que sabia um pouco mais ajudava o outro, ele tinha o espaço pra tá contribuindo. Era interativo, eu acho que eles não tinham nem noção de que cada um estava numa série" (Yo.SO, 2014). A fala de um professor da região norte vai nessa mesma direção: "Então era aquela ajuda mútua: o aluno que saiba ler, ajuda o que não sabe, ou toma leitura, assim, né?” (Ja.N, 2016). Dentre as atividades que possibilitavam o "fazer junto", uma entrevistada cita:

[...] tabuada, era uma coisa que se fazia junto, leitura, era uma coisa que se fazia junto, mas os conteúdos específicos assim [...], alguns dava pra fazer, outros não. Produção de texto, interpretação de texto. Naquele período a gente basicamente estava aprendendo a trabalhar com o tema gerador, então, esse momento, aquela discussão toda era feita com todo mundo, aí depois as partes era dividida, pelos conteúdos, a discussão era feita com todos os alunos (Ca. SO, 2014).

Contudo, um professor formador adverte que alguns professores insistiam em um método tradicional de ensinar. Havia, por parte de alguns professores, resistência em "seguir" as orientações passadas pelas Secretarias de Educação, nos cursos de formação e nas orientações pedagógicas:

Me recordo que um coordenador de área da época falava assim, olha a professora coitada, ela chega a orientar os alunos, ou seja, ela aplica o método da globalização, da palavração, mas antes disso ela já fez pelo ba be bi bo bu. Então aquela "Caminho Suave", aquelas 
cartilhas todas, eram muito utilizadas e o processo da silabação era o que era utilizado (Jb.SO, 2014).

Houve uma rejeição muito grande, mas como havia, digamos a fiscalização e tal, eles se utilizavam dessa estratégia de ensinar pela silabação e ai orientavam os alunos: "olha se vier algum inspetor aqui, vocês vão dizer que nós fomos até a granja e que lá vocês anotaram mentalmente as palavras, o tema gerador era granja, mas vocês anotaram o que viram, vocês viram galinha, vocês viram pintinho". E ai na hora, digamos de ensinar [...] na realidade era pelo sistema antigo, método alfabético e silabação (Jb.SO, 2014).

Depreende-se das entrevistas que o principal objetivo dos professores era instruir os estudantes na aprendizagem e no domínio das letras e contas, o que exigia do corpo docente a transmissão de conteúdos mediante explicação oral e demonstração, com exemplos e materiais didáticos, e, ainda, a utilização da metodologia do estudo do meio ou do laboratório vivencial. ${ }^{5}$ Contudo, conforme já se destacou neste texto, junto com a formação instrucional ocorria, de uma forma ou de outra, a educação e formação de valores. A despeito das possíveis "resistências" dos professores, cabe registrar que a precariedade de materiais didáticos era característica comum à educação do campo nas diversas regiões pesquisadas. Materiais e recursos didáticos são compreendidos, aqui, como o conjunto de "produtos pedagógicos utilizados na educação e, especificamente, como material instrucional que se elabora com finalidade didática" (BANDEIRA, 2011, p.14).

De acordo com os professores, chegavam às escolas cartilhas de alfabetização, e raramente existiam livros didáticos para as demais séries; os professores recorriam a colegas e às "sobras" de materiais de escolas urbanas: "As coisas na zona rural era mais difícil pra chegar, a gente só ficava com as metadinhas, os restos, as sobras, porque, também, era mais difícil o transporte até que chegasse lá, essas coisas assim" (Li.NE, 2015). Essas dificuldades são relatadas também por uma professora de outra região: "[...] a gente não tinha acesso a quase nada naquela época, mas, a gente via aprendizado, né? A gente não tinha nada, desde um cartaz, até as cartolina; a gente aproveitava as fichas de matrícula pra fazer os cartazes" (Lu.SO, 2014). Em situação diferente, algumas entrevistadas disseram que a escola "recebia cadernos e lápis da secretaria de educação" (Or.CS, 2014). Os professores utilizavam recortes de revistas, recursos visuais, como cartazes (aproveitavam cartolinas usadas), fichas de leituras, alfabeto móvel.

[...] a gente ganhava muito material [...], ganhava malas de leitura, ganhava aqueles folders que vinham com sugestões de tema gerador pra gente desenvolver no campo (Va.NE, 2015).

Giz. Mimeógrafo. Stencil. Era uma coisa muito usada naquela época. Depois foi aprimorando, né? Cartolina também. Papel pardo e outros materiais. Inicialmente, livro didático vinha de forma escassa. Mas com o passar do tempo, não (Ca.SO, 2014).

Em relação ao livro didático e às cartilhas, cabe observar que, no início dos anos de 1980, ainda vigoravam as diretrizes do II Plano Setorial de Educação e Cultura para os anos de 1975 a 1979, que previa, na área do então ensino de primeiro grau, implantar o "projeto de desenvolvimento de novas metodologias aplicáveis ao processo ensino-aprendizagem" (CARDOSO, 2012). Como forma de enfrentar os altos índices de evasão escolar e de melhorar a qualidade do ensino, a esta meta se somava a de reformulação dos currículos, formação de pessoal docente, ampliação e melhoria da rede física das escolas e aprimoramento do processo de planejamento e administração escolar. A educação rural aparece associada à preocupação com o baixo índice de escolarização no Brasil devido à quantidade insuficiente de escolas na zona rural,

\footnotetext{
${ }^{5}$ Estudo do meio ou laboratório vivencial - metodologias que propõem tomar o meio em que estão contidos os fenômenos naturais e sociais como fonte de estudo e pesquisa, valendo-se de observação e experimentação para a produção e/ou apropriação de conhecimentos. 
propondo-se, para tanto, a ampliação da oferta educacional nesse contexto. A Seduc-MT elaborou um subprojeto nessa área, que culminou na elaboração de material didático observando-se as especificidades e a cultura regional, a exemplo da Cartilha Ada e Edu ${ }^{6}$. Dessa forma, concorda-se com Oliveira et al. (1984, apud CARDOSO, 2012, p.111) quando dizem que "o livro didático é parte do arsenal de instrumentos que compõem a instituição escolar, parte esta, por sua vez, da política educacional, que se insere no contexto histórico e social".

$\mathrm{Na}$ região nordeste, mais especificamente na microrregião do Araguaia, aconteceram experiências de formulação de cartilha própria, como relata uma das professoras entrevistadas: “[...] A cartilha faz parte desse processo, nós estamos falando da década de 80, então a cartilha da capivara" (Ml.NE, 2014). Nessa região, foi confeccionada, em 1984, a cartilha "Estou lendo", muitas vezes reconhecida pelos temas geradores de suas lições (abóbora, capivara, suçuarana) em lugar de seu nome "oficial". de Mato Grosso:

O livro didático não chegava da mesma forma às escolas das diversas regiões do estado

\begin{abstract}
A gente tinha materiais e tudo, mas não era como a educação na área urbana [...] os nossos materiais, geralmente, era coleção que se pedia para a escola e a gente não tinha assim, às vezes um material mais condizente mesmo com a realidade. Não se trabalhava o tema diretamente com o Estado para o meio rural. Então era uma educação assim mais globalizada, né? (Ce.N, 2014).
\end{abstract}

Para Sacristán (2000), os meios didáticos, especialmente o livro, são os agentes apresentadores do currículo pré-elaborado, os tradutores do currículo aos professores. Por isso, a política curricular deveria se perguntar que tipos de meios podem ser mais úteis para instrumentar o currículo, que sejam eficazes no auxílio ao professor e no desenvolvimento de sua profissionalização, bem como questionar a existência de um controle indireto (e externo) sobre o currículo. Alia-se a isso a contribuição da formação profissional na compreensão das questões curriculares e no aprimoramento da prática pedagógica.

É fala comum entre os entrevistados que o trabalho pedagógico começa a dar sinais de melhoria com os cursos de formação. Os dados indicam que o estado de Mato Grosso teve inúmeras experiências de formação de professores que envolveram, também, os educadores do campo, tais como: Logos II, Homem Natureza, Parceladas, Geração, Inajá, Tucun etc.

Comecei bem "simplesinho". Porque eu fui tirada do meu trabalho [...] Eu era lavradora e de um dia pro outro virei professora. Então, quer dizer, u tinha o nível dos alunos com que eu atuava, a quarta série, e fui adquirindo o conhecimento através dos cursinhos e da formação. Antes de fazer o Projeto Homem Natureza, eu também fiz o LOGOS, eu fiz de 5 a 8 série, todo final de semana eu vinha de lá pra cá, eliminar as matérias (Ca.SO, 2014).

Assim, nos anos de 1990, a forma de organizar o trabalho pedagógico, especialmente em relação às metodologias utilizadas pelos professores de muitas escolas do campo, passa a ter grande relação com os princípios e as práticas que permeavam os cursos de formação que esses professores integravam, a exemplo do "Projeto Homem Natureza", que possibilitava que a prática pedagógica na escola rural fosse "voltada exatamente para a vivência do aluno naquele espaço escolar ou no espaço da comunidade [...] o meio mesmo, onde estava inserida a escola, era o que a gente tinha como laboratório vivencial" (Yo.SO, 2014). O depoimento de outra professora destaca

\footnotetext{
${ }^{6}$ A esse respeito, consultar Cancionila Janzkovski Cardoso, Cartilha Ada e Edu: produção, difusão e circulação. Cuiabá: EdUFMT, 2012.

${ }^{7}$ Sobre essa cartilha, consultar a Dissertação de Mestrado: Cartilha do Araguaia “... Estou lendo!!!”: Seu circuito de comunicação (1978-1989), de Alessandra P. Carneiro Rodrigues. Programa de Pós-Graduação em Educação, da Universidade Federal de Mato Grosso, Campus Universitário de Rondonópolis, 2012. 
o trabalho com projetos: "[...] até 95 a gente não trabalhava projeto, era mais trabalhado a questão mesmo do conteúdo, conceitos. A gente começou a desenvolver alguns projetos foi a partir de 95, com o projeto GerAção" (Ce.N, 2015).

Os cursos de formação de professores, desenvolvidos especialmente após a aprovação da LDB e do FUNDEF, provocaram mudanças na OTP das escolas, tanto do campo quanto da cidade, pois incluíam metodologias de ensino mais problematizadoras, abrindo caminho para o que se espera de uma perspectiva mais crítica da realidade, com possibilidades de superar a fragmentação do saber e das ações pedagógicas.

A prática pedagógica dos professores, em muitos casos, incluía sair da sala de aula e fazer pesquisa no entorno da escola. Assim, como afirma uma professora (Ce.N, 2014), era possível modificar a questão do desenvolvimento da aula, de modo que ficasse "mais palpável mesmo para não ficar aquela coisa muito centrada só na teoria, só na teoria e a pessoa não vê". Buscava-se a relação teoria/prática, escola/vida. Ela destaca, ainda, a influência da professora formadora do Projeto Geração na constituição dessa forma de trabalho, haja vista a motivação para desenvolver as atividades, principalmente no âmbito das ciências, utilizando-se a pesquisa e outros espaços do campo, além da sala de aula. Depoimento nesse mesmo sentido é registrado na fala de uma professora "Yo", da região sudoeste.

Outra forma de organização do trabalho pedagógico caracterizava-se pelos temas geradores e pela problematização da realidade, tomando-se por base as questões sociais da comunidade, que inundavam a sala de aula.

[...] tinha um problema (de conflitos de terra). Então tínhamos que trabalhar com essas crianças e com esses pais das crianças, avós, tios e vizinhos, uma formação completa, inteira, para além do que escreve, mas para aquele que pensa, aquele que compreende o seu entorno, que compreende a problemática que a família está envolvida. Então nós buscávamos textos que contribuíam para a compreensão disso (M1.NE, 2015).

A gente trabalhava com o tema gerador, a gente montava o tema gerador, ai ali dentro a gente ia desenvolvendo os conteúdos semanalmente (Va.NE, 2015).

O estudo de Davis e Gatti (1993) sobre a dinâmica da sala de aula em uma escola rural apontou que o processo de apropriação do conhecimento se caracterizava pela transmissão, memorização e repetição; o processo de construção do conhecimento não era explicitado, uma vez que a professora "nem sempre dominava os conteúdos que ia transmitir" (DAVIS; GATTI, 1993, p. 80). Cabe dizer que, no Brasil, nos anos de 1980 e início de 1990, predominava o ensino tradicional, tendo como exigência básica que o professor transmitisse bem os conteúdos e que os alunos demonstrassem, por meio das provas, terem aprendido aquilo que foi transmitido pelo professor. Certamente, esse tipo de ensino não se manifestava da mesma forma em todas as escolas, assumindo contornos diferenciados conforme o lugar, a composição das turmas de alunos e o perfil das professoras. Contudo, os depoimentos das professoras do estado de Mato Grosso, destacados neste texto, contrapõem-se à realidade apresentada por Davis e Gatti e atestam o quão dinâmico era esse processo, que não era apenas reprodução e transmissão de conhecimento, mas também processo de criação/produção e até mesmo de enfrentamento à lógica academicista e alheia à realidade e às necessidades dos estudantes.

Nas entrevistas realizadas nesta pesquisa, deparou-se com poucas situações semelhantes à descrita por Davis e Gatti (1993), em que o processo se configurava mais como transmissão/repetição do que construção de conhecimentos, o que era condicionado pelos fatores limitantes a que os professores estavam expostos e que, em grande medida, passavam por formação e apoio pedagógico insipientes. A fala abaixo serve para ilustrar essa situação:

A gente não tinha instrução, mas mesmo assim não tinha uma equipe pedagógica, nos apoiando. O planejamento que a gente fazia exigia um professor mais instruído [...] a 
gente recebia os livros para fazer [...] na época o professor seguia muito os pais. Por que tinha um enfoque principal, que era ler, escrever e interpretar, não tinha muito que fazer [...] especificamente até final de 80 , eu recebia esse pedido dos pais. Nas reuniões diziam que o filho tem que saber ler e calcular, ler bem e escrever bem, o resto você deixa quieto. Calcular, interpretar e ler bem, esse era um pedido dos pais, a gente trabalhava mais enfocando isso, se era uma criança de quarto ano, tinha que saber escrever um bilhete, um ofício, uma carta (Ja.SO, 2014). (grifo nosso)

Como se depreende da fala acima, outro fator a ser considerado é que o contexto no qual estava situada a escola, a forma de interlocução que se estabelecia entre pais e escola, bem como as "cobranças" que estes faziam, acabavam influenciando e, até mesmo, modulando a prática pedagógica e o trabalho docente. Tal questão remete ao pensamento de Sacristán (2000, p.202) sobre a complexidade da estrutura da prática pedagógica: "a prática é algo fluido, fugaz, difícil de compreender em coordenadas simples e, além disso, complexa, enquanto nela se expressam múltiplos determinantes, valores e usos pedagógicos"; entre esses determinantes, podem-se destacar os institucionais, os organizativos, as tradições metodológicas, as condições físicas e materiais e as possibilidades reais dos professores. Therrien (1991) argumenta que as professoras rurais leigas, no exercício de suas funções, de uma forma ou de outra, acabavam levando em conta os interesses dos trabalhadores em termos de suas lutas, sua cultura e suas formas de produção, que passam a constituir o seu saber social, fazendo com que se tornem sujeitos de práticas pedagógicas heterogêneas (GARCIA; MACHADO, 2017).

No contexto em análise, constatou-se que a relação entre escola e comunidade era um fator que contribuía enormemente para a estruturação e o funcionamento da escola. Havia uma proximidade grande entre comunidade (pais, principalmente) e escola/professora, até mesmo porque esta era a única trabalhadora da escola e, mais do que nunca, precisava recorrer à comunidade para fazer a instituição funcionar - em muitos momentos, por exemplo, providenciando lenha para o fogão de modo a preparar a merenda, procedendo à poda do mato e limpeza do pátio da escola: “[...] naquela época a gente não tinha nada, era fogãozinho a lenha ainda, então os pais ajudavam, por exemplo, com lenha, se tinha que fazer um mutirão pra limpar o quintal, eles ajudavam, tinha uma horta também que a gente cultivava [...]" (Lu.SO, 2014). Destaca-se, também, a participação dos pais na gestão político-pedagógica da escola, como no caso das escolas situadas em assentamentos rurais.

[...] desde o nome das escolas foi escolhido os pais que escolheram. Então tudo era reunido e discutido no espaço da escola, os pais participavam e decidiam sobre a escola [...] Quando faltava água [...] os pais levavam água para fazer a merenda, os pais ajudavam e participavam de tudo. A escola era o centro, a escola era a igreja, onde celebrava as missas, onde fazia as reuniões da associação. Então, a escola era o centro do assentamento, do movimento (Mg.SE, 2015).

Os pais sempre muito presentes na escola, a gente sempre chamava os pais e eles vinham [...] Então havia essa responsabilidade, mas muito forte mesmo onde tinha o MST [...] (Ma.SE, 2015)

Nos diversos depoimentos colhidos, fica patente o enorme respeito que os pais/comunidade tinham pela escola e pela professora nessa época, o que fazia com que houvesse grande retorno quando eram chamados a conversar sobre o desenvolvimento escolar dos filhos e sobre a escola.

\section{CONSIDERAÇÕES FINAIS}

Procurou-se, neste texto, analisar os processos relativos à organização do trabalho pedagógico nas escolas do campo no estado de Mato Grosso, nas décadas de 1980 e 1990, 
considerando quatro eixos de análise, que se articulam: condições de trabalho, orientação/acompanhamento do trabalho pedagógico, princípios e fundamentos educativos e organização do trabalho pedagógico.

Os relatos apresentados nesta pesquisa demonstram que eram poucas as condições efetivas de se acompanhar o trabalho pedagógico desenvolvido nas escolas do campo; o objetivo predominante das secretarias era garantir o funcionamento dessas escolas, realizando visitas quando possível e oferecendo orientações básicas para o funcionamento, entregando merenda, algum material didático e dando sugestões face a alguma dificuldade apresentada pelo professor. Assim, na lida cotidiana, os professores iam, individualmente, buscando soluções para os problemas que surgiam, por tentativa e erro, contando com auxílios esporádicos, na maioria das vezes. Essas dificuldades não impediam, porém, que as secretarias de educação cobrassem um planejamento de ensino, assim como um resultado, o que incluía, não raro, a aplicação de provas e testes para se assegurarem do que os alunos haviam aprendido.

Os professores atuavam em condições adversas, a começar pelo aspecto da formação profissional insuficiente - a maioria tinha o equivalente ao ensino fundamental, nos anos de 1980, e ao ensino médio, nos anos de 1990, de modo que o aprendizado da docência se dava no próprio ato de ensinar, mediado pelos cursos de formação continuada e de formação inicial. Outra dificuldade enfrentada eram os problemas de deslocamento e locomoção campo-cidade, ficando os professores, muitas vezes, isolados devido às péssimas condições das estradas e às distâncias. E, finalmente, havia o fato de que, em grande parte das escolas, os recursos e materiais didáticos chegavam de forma inconstante e regrada, o que levava os professores a buscarem materiais com outros colegas e a reaproveitarem material usado em outras escolas.

Em relação às formas de organização do trabalho pedagógico - espaço-tempo, organização das turmas, organização curricular, metodologias etc - , com base nos depoimentos dos professores, verificou-se: a predominância das turmas multisseriadas; o uso de metodologias focadas na transmissão/memorização do conteúdo, mesclando-se o atendimento individualizado ao aluno com atividades grupais/coletivas e, ainda, o uso de metodologias participativas e investigativas, baseadas no estudo do meio e laboratório vivencial; a organização curricular por disciplinas fragmentadas, por projetos de trabalho e por temas geradores, constatando-se a influência dos cursos de formação de professores na adoção de uma perspectiva curricular e de práticas pedagógicas mais abertas e críticas.

É mister concordar com Sacristán (2000) quando ele afirma que a prática pedagógica é um trabalho complexo, uma vez que a escola e o professor têm que responder, com o currículo, a necessidades sociais e culturais diversas, o que implica ao professor conectar conhecimentos de tipos muitos diversos na hora de atuar; as condições de formação profissional não costumam ser as mais adequadas, assim como as condições nas quais realiza seu trabalho. Por isso, não está ao alcance de todos os professores planejar sua prática curricular partindo de orientações, princípios e saberes gerais. De algum modo, os professores passam a servir de "pré-elaborações" que "préplanejam" sua prática (SACRISTÁN, 2000, p.149), ou seja, de pré-elaborações do currículo para o ensino, presentes na tradição profissional acumulada e nos agentes externos que oferecem o currículo elaborado.

Em meio aos desafios e às contradições vivenciadas na educação do campo nas décadas de 1980 e 1990, é válido ressaltar a função social cumprida pelas escolas do campo ao propiciarem o acesso ao conhecimento sistematizado e a socialização cultural dos filhos dos trabalhadores e trabalhadoras rurais. No período em questão, evidenciou-se que essa modalidade de ensino não era concebida em suas especificidades pelos agentes públicos e pelas políticas públicas, inserindo-se, de maneira secundária, nas políticas gerais de educação. Cabe lembrar que aqui se fala de um período em que a educação do campo era denominada de educação rural, cuja especificidade foi mencionada somente na LDB de 1996, em seu artigo 28, mesmo que os movimentos sociais do campo já acenassem para a constituição de um projeto de educação do 
campo, o que efetivamente aconteceria no I Encontro Nacional de Educadores e Educadoras da Reforma Agrária - ENERA - no ano de 1997, em Luziânia, Goiás. A configuração da educação do campo, como concepção e como política pública recente, está presente nas falas dos professores entrevistados, conforme destacamos abaixo, a título de exemplo:

Foi a partir de pouco tempo que a gente vem tendo essa visão de mostrar à população que o campo é um lugar especifico que deve ser valorizado e conhecido como tal, e que também é um lugar para que o povo permaneça ali, no seu meio. Para não haver a questão do êxodo rural, que acontece muito com a questão da desvalorização [...] (Ce.N, 2014).

[...] a educação do campo vem se desenhando a partir dos anos 2000, com as conferências, com as conquistas no bojo da luta, e que hoje está ali, está tendo hoje várias formações nesse sentido. Tem a formação continuada de educação do campo, hoje está tendo formação inicial [...] Educação do campo, não é (apenas) formação para o campo, é formação para humanizar e politizar os sujeitos (Ma.SE, 2015).

Conforme evidenciado nos depoimentos, a educação do campo é fruto das lutas dos trabalhadores, articulados em torno dos movimentos sociais do campo. A educação do campo insere-se em uma lógica de educação emancipadora, que pressupõe a existência e a potencialização de instrumentos teórico-práticos que habilitem os sujeitos a uma apropriação crítica do conhecimento, da ciência, na perspectiva de uma melhor compreensão da realidade e de uma formação que projete o desenvolvimento humano e social, na dimensão pessoal e, também, na coletiva. É, portanto, uma educação que se vincula a uma concepção de formação omnilateral, na perspectiva de aprimorar todas as potencialidades criativas da pessoa e, por isso, não pode prescindir de articular educação e trabalho, educação, cultura e tecnologia. Nessa concepção, "O campo assume a dimensão de espaço histórico da disputa pela terra e pela educação, superando o rural que não considera os camponeses como sujeitos da produção de saber, conhecimento, cultura, linguagem, arte e história" (RIBEIRO, 2013. p.3).

Não se defende aqui uma escola específica para o campo, mas, sim, do campo e de seus sujeitos, em reconhecimento às especificidades que foram desconsideradas historicamente, na pretensa universalização de direitos. Fala-se de um campo diverso - dos agricultores familiares e camponeses, das comunidades indígenas, ribeirinhas e quilombolas, entre outros - que exige, por parte Estado, viabilizar as plenas condições de funcionamento das escolas, conforme estabelecido na política nacional de educação do campo e em suas leis complementares. Da parte dos profissionais da educação, de estudantes e pais, cabe uma firme atuação, como exercício de participação coletiva e democrática, no sentido de materializar, no âmbito de cada comunidade, um projeto educativo correspondente à perspectiva de construção de uma nova sociabilidade no campo e na cidade.

Espera-se que o presente estudo possa trazer maior visibilidade à educação do campo, possibilitando a compreensão de processos vividos e fornecendo indicadores para outras ações necessárias, como a proposição de políticas mais consistentes, que reconheçam os saberes já produzidos e a diversidade do campo, além de registrar parte da história da educação no estado de Mato Grosso, cuja vida social e econômica se pauta, prioritariamente, nas atividades desenvolvidas no campo.

\section{REFERÊNCIAS}

ARROYO, Miguel. G. Prefácio: Escola de direito. In: ANTUNES-ROCHA, Maria Isabel; HAGE, Salomão M. (Org.). Escola de direito: reinventando a escola multisseriada. Belo Horizonte: Autêntica, 2010. p. 9-14.

BANDEIRA, Denise. Materiais Didáticos. Curitiba, PR: IESDE, 2009. Disponível em: 
https://www.academia.edu/10850993/Materiais_did\%C3\%A1 ticos. Acesso em: 29 maio 2019.

CALAZANS, Maria Julieta C. Para compreender a educação do Estado no meio rural - traços de uma trajetória. In: THERRIEN, Jacques; DAMASCENO, Maria N. (Org.). Educação e escola no campo. Campinas: Papirus, 1993. p.15-42.

CALDART, Roseli S. I seminário com as escolas de inserção dos estudantes. In: CALDART, Roseli S. (Org.). Caminhos para a transformação da escola. São Paulo: Expressão Popular, 2010. p.1322.

CALDART, Roseli S. Sobre a Especificidade da Educação do Campo e os desafios do Momento Atual. 2015. Disponível em: file:///C:/Users/Windows/Downloads/EdoC-DesafiosMomentoAtual-RoseliJul15\%20(6).pdf. Acesso em: 04 dez. 2020.

CARDOSO, Cancionila J. Cartilha Ada e Edu: produção, difusão e circulação. Cuiabá: EdUFMT, 2012.

CASAGRANDE, Nair. A pedagogia socialista e a formação do educador do campo no século XXI: as contribuições da Pedagogia da Terra. 2007. Tese (Doutorado em Educação). Universidade Federal do Rio Grande do Sul, Faculdade de Educação. Porto Alegre, 2007.

DAVIS, Cláudia; GATTI, Bernadete. A dinâmica da sala de aula na escola rural. In: THERRIEN, Jacques; DAMASCENO, Maria N. (Org.). Educação e escola no campo. Campinas: Papirus, 1993. p.75-135. (Coleção magistério. Formação e trabalho Pedagógico)

FREIRE, Paulo. Pedagogia da Autonomia. 25ª ed. Rio de Janeiro: Paz e Terra, 2002.

FREITAS, Luís C. Crítica da organizaçãa do trabalho pedagógico e da didática. Campinas: Papirus, 1995.

FRIGOTTO, Gaudêncio; CIAVATTA, Maria; RAMOS, Marise N. O trabalho como princípio educativo. Disponível em:

http://www.pb.iffarroupilha.edu.br/site/midias/arquivos/201179171745208frigotto_ciavatta_ra mos_o_trabalho_como_principio_educativo.pdf. Acesso em: 28 fev. 2019.

FRIZZO, Giovanni. O trabalho pedagógico como referência para a pesquisa em educação física. Revista Pensar a Prática, v. 11, n. 2, Goiânia: Editora da UFG, 2008. p.1-10. Disponível em: https://www.revistas.ufg.br/fef/article/view/3535. Acesso em: 29 maio 2019.

GARCIA, Luana S.N.; MACHADO, Ilma F. Retrato do ensino rural no município de Cáceres, nas décadas de 1980 e 1990. Revista Pedagogia, UFMT, no 7 Jul/Dez 2017. p.134-141.

GENTIL, Heloisa S. Formação docente - no balanço da rede entre políticas públicas e movimentos sociais. Dissertação de Mestrado. PPGE/UFRGS. Porto Alegre, 2002.

GENTIL, Heloisa S. Identidades de professores e rede de significações - configurações que constituem o "nós, professores". Tese (Doutorado em Educação). Programa de Pós-graduação da Universidade Federal do Rio Grande do Sul. Porto Alegre, 2015. 302p.

GAMBOA, Silvio S. Pesquisa em educação: métodos e epistemologias. 2. ed. Chapecó: Argos, 2012. 
HAGE, Salomão M. Movimentos sociais do campo e afirmação do direito à educação: pautando o debate sobre as escolas multisseriadas na Amazônia paraense. Revista Brasileira de Estudos Pedagógicos. Brasília, v. 87, n. 217, set./dez. 2006. p. 302-312.

MACHADO, Ilma F. A organização do trabalho pedagógico em uma escola do MST e a perspectiva de formação omnilateral. Tese (Doutorado). Universidade Estadual de Campinas, Faculdade de Educação. Campinas, 2003.

MACHADO, Ilma F. Um projeto político-pedagógico para a escola do campo. Cadernos de Pesquisa Pensamento Educacional, n. 8, vol. 4, jul.-dez., 2009. p.1-10.

MARX, Karl. A Ideologia Alemã. São Paulo: Expressão Popular, 2009.

MOLINA, Monica C.; OLIVEIRA, Liliane L.N.A.; MONTENEGRO, João L.A. Das desigualdades aos direitos: a exigência de políticas afirmativas para a promoção da equidade educacional no campo. Brasília: CDES/Sedes, 2009. Disponível em: www.gepec.ufscar.br/publicacoes/. Acesso em: 11 jul. 2019.

MOLINA, Monica C.; FERNANDES, Bernardo M. O campo da educação do campo. In: MOLINA, Monica C.; AZEVEDO DE JESUS, Sônia M. (Orgs.). Contribuições para a construção de um projeto de educaşão do campo. Brasília, DF: Articulação nacional por uma educação do campo, 2004. p.32-53.

MOLINA, Monica C.; ANTUNES-ROCHA, Maria Isabel. Educação do campo: história, práticas e desafios no âmbito das políticas de formação de educadores - reflexões sobre o Pronera e o Procampo. Revista Reflexão e Ação, Santa Cruz do Sul, v.22, n.2, jul./dez.2014. p.220253. Disponível em: http://online.unisc.br/seer/index.php/reflex/index. Acesso em: 04 dez. 2020.

OLIVEIRA, Maria Rita D.; OLIVEIRA, Nazareno S.S. Classes multisseriadas: práticas, memórias e formação docente. Revista Margens Interdisciplinar. v. 9, n. 12, UFPA: Editora Campus de Abaetetuba, p.224-233, 2015.

PERIPOLLI, Odimar J. Um olhar sobre (o campo) a educação no/do campo: A questão das especificidades do ensino. Revista da Faculdade de Educação, Ano VIII no 13, Jan./Jun. Cáceres: Ed. Unemat, 2010. p.51-62.

PISTRAK, Moisey. Fundamentos da escola do trabalho. São Paulo: Expressão Popular, 2002.

RIBEIRO, Marlene. Movimento camponês: trabalho e educação. São Paulo: Expressão Popular, 2010.

RIBEIRO, Marlene. Política educacional para populações camponesas: da aparência à essência. Revista Brasileira de Educação, v. 18 n. 54 jul.-set. 2013. P.669-796. Disponível em: https://www.scielo.br/pdf/rbedu/v18n54/09.pdf. Acesso em: 03 dez. 2020.

ROCHA, Simone A. Formação de professores em Mato Grosso: trajetória de três décadas (1977-2007). Cuiabá: EdUFMT, 2010.

SACRISTÁN, José G. O currículo: uma reflexão sobre a prática. Porto Alegre: ARTMED, 2000. 
SILVA, Rose M.; ANDRIONI, Ivonei; MACHADO, Ilma F. Ensino médio integrado: acirrar contradições e abrir brechas. Revista Labor. Edição Especial. vol. 02, n 18 . Fortaleza/CE, nov. 2017, p.78-92.

SOUZA, Maria Antônia de. (Org.). Escola pública, educaşão do campo e projeto político-pedagógico. Curitiba: UTP, 2018.

TARDIF, Maurice; LESSARD, Claude. O Trabalho Docente: elementos para uma teoria da docência como profissão de interações humanas. Petrópolis: Vozes, 2007.

THERRIEN, Jacques. A professora leiga e o saber social. In: Brasil, ME. Professor leigo: institucionalizar ou erradicar. São Paulo: Cortez, 1991.

VENDRAMINI, Célia R. Educação do campo: uma educação virada para o futuro? In: CANÁRIO, Rui; RUMMERT, Sonia M. Mundos do trabalho e da aprendizagem (Org.). Lisboa: EDUCA, 2009. p.97-106.

Submetido: $07 / 10 / 2019$

Aprovado: $11 / 12 / 2020$ 